\title{
SYNTHESIS AND CHARACTERIZATION OF LIGNIN-BASED ADHESIVE CROSS-LINKED WITH FURFURYL ALCOHOL-FORMALDEHYDE AND EPOXY RESINS
}

\author{
JUN ZHANG, ${ }^{*}$ XUEDONG XI, ${ }^{* *}$ XIAOJIAN ZHOU, ${ }^{*}$ JIANKUN LIANG, $^{* * *}$ \\ GUANBEN DU* and JUN CAI ${ }^{* * * *}$ \\ "Yunnan Key Laboratory of Wood Adhesives and Glue Products, Southwest Forestry University, Kunming \\ 650224, People's Republic of China \\ ***ENTIB-LERMAB, University of Lorraine, 27, Philippe Seguin Str., 88051 Epinal Cedex 9, France \\ ${ }^{* * * *}$ Kaili University, Kaili 556011, People's Republic of China \\ ${ }^{* * * * *} Y u n n a n$ Education Publishing House, Kunming 650032, People's Republic of China \\ $\square$ Corresponding authors: Jiankun Liang, Dushimensheng@126.com \\ Xiaojian Zhou,xiaojianzhou@hotmail.com
}

Received November 15, 2018

Lignin extracted from corn stalk was cross-linked with furfuryl alcohol-formaldehyde (FF) resin in the laboratory to prepare a bio-based adhesive, with good water resistance, for producing particleboard. The results of matrix-assisted laser desorption-ionization time-of-flight mass spectroscopy and ${ }^{13} \mathrm{C}$ nuclear magnetic resonance spectroscopy indicated that furfuryl alcohol reacted with formaldehyde under acidic conditions. The $-\mathrm{CH}-(\mathrm{OH})-\mathrm{groups}$ were involved in the cross-linking of the lignin-furfuryl-formaldehyde (LFF) adhesive. The internal bond strength of the LFF-bonded particleboard showed that the cured LFF was improved and had higher performance compared to the lignin-furfuryl alcohol (LF) adhesive. The LFF with 9\% epoxy resin adhesive had an excellent modulus of elasticity, which was higher than those of PF and LF adhesives.

Keywords: lignin-based adhesive, furfuryl alcohol-formaldehyde resin, EPR resin, internal bond strength

\section{INTRODUCTION}

Bio-materials from forestry or agriculture have attracted increasing attention in the wood adhesive industry, ${ }^{1-4}$ with mounting concerns about the toxicity of phenolic products. ${ }^{5}$ Among these materials, lignin has been intensively studied due to its similar structure to that of phenol. ${ }^{6-9}$ However, lignin as an adhesive has a poor gluing property and weak water resistance because of its complex structure and low reactivity. ${ }^{10}$ Approximately 55 million tons of lignin per year resulting as waste products from the pulp and paper industry are burned or discarded, and only a small amount of lignin is used to prepare low-value industrial products. ${ }^{11}$ Furfuryl alcohol comes from the hydrolysis of plant biomass and has been widely used due to its structure stability and good water resistance. ${ }^{12-14}$ The hydroxymethyl group of furfuryl alcohol can easily react with the phenol ring of lignin under acid conditions for further polymerization to improve the binding strength and water resistance of lignin-based adhesive. However, the furfuryl alcohol self-condensation reaction ${ }^{15,16}$ predominates to an extent that leads to slight or no co-reaction with lignin. This case can lead to a short storage period of the adhesive, which is undesirable for adhesive application. Fortunately, the bridge linkage between formaldehyde and furfuryl alcohol is easy to form as the self-condensation of furfuryl alcohol decreases. Meanwhile, the furfuryl alcohol-formaldehyde adhesive ${ }^{17}$ presents a good bonding performance and excellent water resistance. The molecular structure of EPR contains numerous active epoxy groups ${ }^{18-20}$ which can accelerate the polymerization of lignin and furfuryl alcohol 
during the adhesive curing process. Thus, a lignin-based adhesive cross-linked with furfuryl alcohol, formaldehyde and EPR, with good water resistance, must be developed.

In this study, formaldehyde was used as a cross-linker of furfuryl alcohol under acidic conditions. Furfuryl alcohol-formaldehyde (FF) resin and lignin were examined to ascertain the feasibility of lignin-furfuryl-formaldehyde (LFF) adhesives with good water resistance. Afterward, the EPR was mixed with LFF for further polymerization during curing. This study is important for the development of a lignin-based wood adhesive with a view to replace industrial wood adhesives prepared with petrochemicals.

\section{EXPERIMENTAL}

\section{Materials}

Lignin extracted from corn stalk residue after the hydrolysis of hemicelluloses was supplied by Long Live Biological Technology Company (Shangdong, China), with the following composition: $92.33 \%$ Klason lignin, 5.38\% acid-soluble lignin and $2.29 \%$ cellulose.

Formaldehyde (47\% purity) and furfuryl alcohol (98\% purity) were purchased from Acros Organics (Geel, Belgium).

Beech particleboards (Fagus sylvatica), with 9\%-10\% moisture content, and PF control adhesive (molar ratio $\mathrm{F} / \mathrm{P}=2.2$ ) were supplied by XinFei Lin Panel Company (Kunming, China).

Commercial EPR (E-44) was purchased from Sinopharm Chemical Reagent Company (Beijing, China).

\section{Preparation of LF and LFF adhesives}

The LF adhesive was synthesized under the following conditions: $35 \mathrm{~mL}$ furfuryl alcohol and 100 $\mathrm{mL}$ distilled water were mixed in a beaker; after stirring for $2 \mathrm{~min}, 70 \mathrm{~g}$ of lignin was added to the solution, which was stirred for $30 \mathrm{~min}$ at $60{ }^{\circ} \mathrm{C}$ under the acidic condition to form the LF adhesive. During the process, the $\mathrm{pH}$ was adjusted using $30 \%$ acetic acid solution and was controlled at $\mathrm{pH} 5$.
The LFF adhesive was prepared using the following process: $28.9 \mathrm{~mL}$ formaldehyde, $35 \mathrm{~mL}$ furfuryl alcohol, and $100 \mathrm{~mL}$ distilled water were mixed in a flat-bottom flask with a thermometer and magnetic stirrer bar at $60{ }^{\circ} \mathrm{C}$ for $30 \mathrm{~min}$ for the $\mathrm{FF}$ resin preparation. During the process, $30 \%$ acetic acid was used to adjust the $\mathrm{pH}$ to 5 . Afterwards, $70 \mathrm{~g}$ lignin was added at $60{ }^{\circ} \mathrm{C}$ for $30 \mathrm{~min}$ to obtain the LFF adhesive.

The gel times and the content of formaldehyde emission of LF, LFF, and PF resins were determined according to the Chinese standards GB/T14074 9 (2006) and GB/T18580 (2017). The Tu-4 viscosity cup was used to test the viscosities of these resins. For the gel time test, $10 \mathrm{~g}$ of resin was placed into a test tube, which was then immersed in a boiling water bath (100 ${ }^{\circ} \mathrm{C}$ ) and was gently, continuously, and rapidly stirred with a muddler using an upward-downward movement until gelation occurred. The gel time was measured from the start of the immersion of the resin in boiling water. The solidity of various resins was measured by testing the weight of the resins before and after drying at $120 \pm 1{ }^{\circ} \mathrm{C}$ in an oven for $2 \mathrm{~h}$. The characteristics of the different resins are shown in Table 1.

\section{Particleboard preparation}

Duplicates of one-layer laboratory particleboard $(350 \mathrm{~mm} \times 350 \mathrm{~mm} \times 14 \mathrm{~mm})$ were prepared at $195{ }^{\circ} \mathrm{C}$ for $8 \mathrm{~min}$, using beech particles under a maximum pressure of $28 \mathrm{~kg} / \mathrm{cm}^{2}$. The solid content of the resin based on dry wood particles was maintained at $10 \%$. The LFF resin was mixed with different amounts of EPR (weight percentages of 3,6, and 9) with stirring for $3 \mathrm{~min}$ before mixing them with the particles. The particleboard panel based on LF resin with $9 \%$ EPR or PF resin with $9 \%$ EPR was prepared under the same conditions for the comparison. All the particleboard panels were measured for the dry and wet internal bond (IB) strength, ${ }^{21}$ using an Instron 4476 universal testing machine (Instron, Boston, USA). IB and thickness swelling tests in boiling water were implemented according to Chinese National Standard GB/T17657 (2006). Each result was presented as the average value of eight specimens.

Table 1

Characterization of laboratory-made PF and lignin-based resins

\begin{tabular}{lcccc}
\hline $\begin{array}{l}\text { Resin } \\
\text { type }\end{array}$ & $\begin{array}{c}\text { Solid content } \\
(\%)\end{array}$ & $\begin{array}{c}\text { Viscosity } \\
(\mathrm{s})\end{array}$ & $\begin{array}{c}\text { Curing time } \\
(\mathrm{s})\end{array}$ & $\begin{array}{c}\text { Formaldehyde emissions } \\
\left(\mathrm{mg} \cdot 100 \mathrm{~g}^{-1}\right)\end{array}$ \\
\hline LF & 36 & $54 \pm 2$ & $402 \pm 2$ & 0 \\
LFF & 47 & $76 \pm 2$ & $143 \pm 2$ & 5.33 \\
PF & 52 & $78 \pm 2$ & $126 \pm 3$ & 8.23 \\
\hline
\end{tabular}

${ }^{13} \mathrm{C}$-NMR spectroscopy

A super conducting magnetic resonance imaging (MRI) apparatus (Bruker-AVANCE 600, Switzerland) was used to detect the FF and LFF resins. The resonance frequency was $150 \mathrm{MHZ}$. $300 \mu \mathrm{L}$ of the samples and $100 \mu \mathrm{L}$ deuterium generation solvent dimethyl sulfoxide (DMSO-d6) were mixed for testing. The test conditions were as follows: relaxation delay 
time was $6 \mathrm{~s}$; the scanning accumulative number was 500 times to 800 times.

\section{MALDI-TOF-MS spectrometry}

Mass spectrometry detection of FF and LFG resins was implemented using a KRATOS Kompact MALDI 4 instrument (AXIMA Performance, Shimadzu). First, different resins were dissolved in acetone $(10 \mathrm{mg} / \mathrm{mL})$. Afterwards, 2,5-dihydroxy benzoic acid $\left(\mathrm{C}_{7} \mathrm{H}_{6} \mathrm{O}_{4}\right)$ as the matrix was mixed with $\mathrm{NaCl}(10 \mathrm{mg} / \mathrm{mL})$ for ion-formation enhancement. The resin and matrix solutions were mixed according to the following proportions: 3 parts adhesive solution, 3 parts matrix solution, and 1 part $\mathrm{NaCl}$ solution. Afterwards, 0.5-1 $\mu \mathrm{L}$ of the mixed solution was placed on the MALDI target. After the evaporation of the solvent, the MALDI target was introduced into the spectrometer. The irradiation source was a pulsed nitrogen laser with a $337 \mathrm{~nm}$ wavelength, and the duration of a single laser pulse was 3 ns. The measurement conditions were as follows: polarity-positive, flight path-linear, mass-high with $20 \mathrm{kV}$ acceleration voltage and $100-150$ pulses per spectrum. The delayed extraction technique was used by applying delay times of 200-800 ns. ${ }^{15}$

Table 2

Results of laboratory-made particleboards bonded with lignin-based adhesives

\begin{tabular}{lcccc}
\hline $\begin{array}{l}\text { Particleboard } \\
\text { type }\end{array}$ & $\begin{array}{c}\text { Dry IB strength } \\
(\mathrm{MPa})\end{array}$ & $\begin{array}{c}\text { Wet IB strength } \\
(\mathrm{MPa})\end{array}$ & $\begin{array}{c}\text { Density } \\
\left(\mathrm{kg} \cdot \mathrm{m}^{-3}\right)\end{array}$ & $\begin{array}{c}\text { Thickness } \\
\text { swelling (\%) }\end{array}$ \\
\hline LF & $0.25 \pm 0.03$ & $/$ & 642 & $27.88 \pm 1.63$ \\
PF & $0.51 \pm 0.02$ & $0.30 \pm 0.03$ & 688 & $6.77 \pm 1.33$ \\
LFF & $0.38 \pm 0.03$ & $0.23 \pm 0.02$ & 666 & $18.85 \pm 1.53$ \\
LFF+3\%EPR & $0.41 \pm 0.03$ & $0.27 \pm 0.02$ & 653 & $15.27 \pm 1.61$ \\
LFF+6\%EPR & $0.43 \pm 0.02$ & $0.31 \pm 0.03$ & 672 & $11.76 \pm 1.55$ \\
LFF+9\%EPR & $0.47 \pm 0.03$ & $0.33 \pm 0.02$ & 696 & $7.18 \pm 1.26$ \\
LF+9\%EPR & $0.32 \pm 0.03$ & $/$ & 667 & $25.38 \pm 1.55$ \\
PF+9\%EPR & $0.56 \pm 0.02$ & $0.38 \pm 0.04$ & 689 & $6.53 \pm 1.21$ \\
\hline
\end{tabular}

\section{Thermomechanical analysis (TMA)}

The elasticity modulus (MOE) of different lignin-based adhesives or PF adhesive were obtained using a TMA instrument (Mettler-Toledo, SDTA840, New York, USA) with STARe software (Mettler-Toledo, Version 14.0, New York, USA) for data treatment. The heating rate was $20{ }^{\circ} \mathrm{C} / \mathrm{min}$, and the temperature range was $25^{\circ} \mathrm{C}$ to $250{ }^{\circ} \mathrm{C}$.

\section{RESULTS AND DISCUSSION Performance of particleboard prepared with lignin-based adhesive}

The properties of the produced particleboards based on the lignin-based and PF adhesives are gathered in Table 2. Compared with other panels prepared with LFF-based adhesives, the LFF+9\%EPR panel possessed the highest dry and wet IB strengths after $2 \mathrm{~h}$ in boiling water (averaged at $0.47 \mathrm{MPa}$ and $0.33 \mathrm{MPa}$ ) and have lowest thickness swelling in $2 \mathrm{~h}$ (averaged at $7.18 \%$ ). The results indicate that, under acidic conditions, the addition of EPR to the LFF resin improved the bonding property of the adhesive, and with the increase of EPR, the IB strength and water resistance of the particleboards increased. The LF adhesive might involve a predominant self-polymerization of furfuryl alcohol to minimize the co-condensation between lignin and furfuryl alcohol; the panel based on LF or LF+9\%EPR adhesive without water resistance showed a lower IB strength, compared with the LFF adhesive. The result indicated that formaldehyde reacts with furfuryl alcohol to decrease the self-condensation under acidic conditions, and the cross-linking between lignin and FF resin under acidic conditions has been easily proven. The value of dry IB strength of LFG+9\%EPR panel was close to that of the PF panel. Moreover, after $2 \mathrm{~h}$ treatment in boiling water, the value of IB strength of LFG+9\% EPR panel was higher than that of the PF panel. The reaction between $\mathrm{PF}$ resin and EPR has been established according to the performance results of $\mathrm{PF}+9 \% \mathrm{EPR}$ panel, which shows the highest dry and wet IB strengths after $2 \mathrm{~h}$ in boiling water. Thickness swelling of LFG+9\%EPR panel after 2 $\mathrm{h}$ in boiling water was enough to meet the requirements of the Chinese national standard (G/BT 4897.5, $\leq 8 \%$ ). Meanwhile, from Table 1, we can see that the formaldehyde emission content of LFF was $5.33 \mathrm{mg} / 100 \mathrm{~g}$, which meets the Chinese national standard (GB/T18580, $\leq 9$ $\mathrm{mg} / 100 \mathrm{~g}$ ). Further industrial optimization for possible future industrial production is necessary, 
but the LFG+9\%EPR adhesive appears competitive with the LF and PF adhesives.

\section{${ }^{13}$ C-NMR spectroscopy}

The ${ }^{13} \mathrm{C}-\mathrm{NMR}$ spectra of the FF resin and LFF adhesive are shown in Figures 1 and 2. From both pictures, we can see that the absorption peaks at 60.05-60.74 ppm and 87.58-87.71 ppm correspond to the methylene groups of furfuryl alcohol and hemiacetal, respectively; this result indicates that the reaction between formaldehyde and furfuryl alcohol has been established under acidic conditions according to the reaction mechanism shown in Scheme 1. The 56.08-56.41 ppm values shown in Figure 1 belong to the hydroxymethyl group of furfuryl alcohol and indicate that some residual resin reactivities are still present, but cannot be shown in Figure 2. The result indicated that lignin cross-linked with the residual resin for further polymerization. The methylene $\left(-\mathrm{CH}_{2}-\right)$ bridges due to furfuryl alcohol self-condensation correspond to the peak region near $30 \mathrm{ppm}$ according to literature. ${ }^{12}$ The spectrum of the FF resin and LFF adhesive, instead, did not present any peak in the $30 \mathrm{ppm}$ region, indicating that formaldehyde as a coupling reagent cross-linked with furfuryl alcohol to avoid the self-condensation of furfuryl alcohol. In Figure 2, we found that the $27.87 \mathrm{ppm}$ value corresponds to the absorption peak of the propane group of lignin, and $167.71 \mathrm{ppm}$ and $176.53 \mathrm{ppm}$ belong to the absorption peak of the hydroxyl groups of the benzene ring of lignin. The peak at $67.67 \mathrm{ppm}$ shown in Figure 2 corresponds to the methylene $\left(-\mathrm{CH}_{2}-\right)$ bridges between the hemiacetal group of furfuryl alcohol and lignin as the reaction mechanism shown in Scheme 1. The peak of 25.19 ppm presented in Figure 2 belongs to the methylene $\left(-\mathrm{CH}_{2}-\right)$ bridges between the self-condensation of lignin with formaldehyde as a cross-linking agent; the reaction mechanism is shown in Scheme 2. These results indicate that the cross-linking between formaldehyde and furfuryl alcohol occurs under acidic conditions and effectively avoids the self-condensation of furfuryl alcohol. The reaction between FF resin and lignin or between formaldehyde and lignin has been also proven.
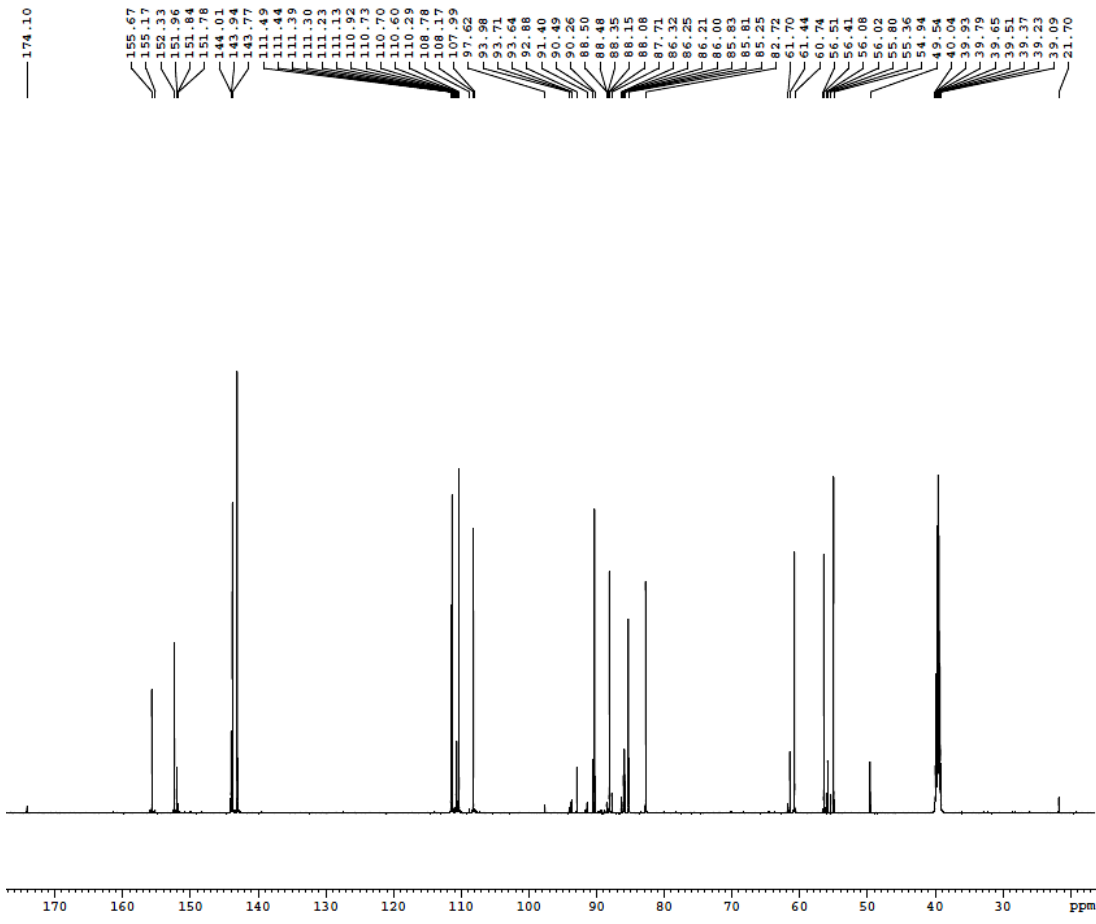

Figure 1: ${ }^{13} \mathrm{C}-\mathrm{NMR}$ spectrum of FF resin in the acid system 


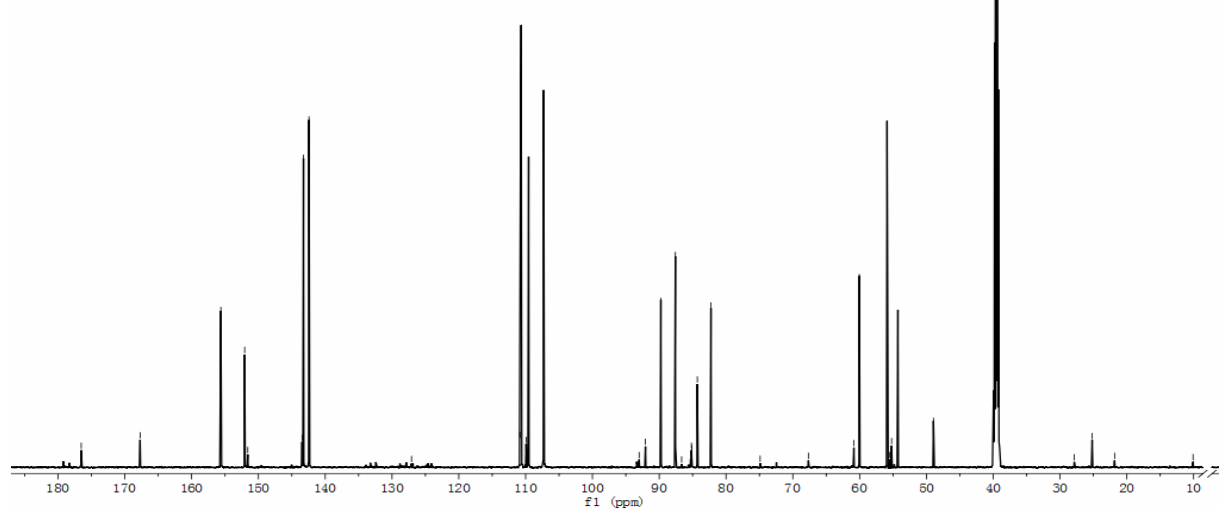

Figure 2: ${ }^{13} \mathrm{C}-\mathrm{NMR}$ spectrum of LFF resin in the acid system
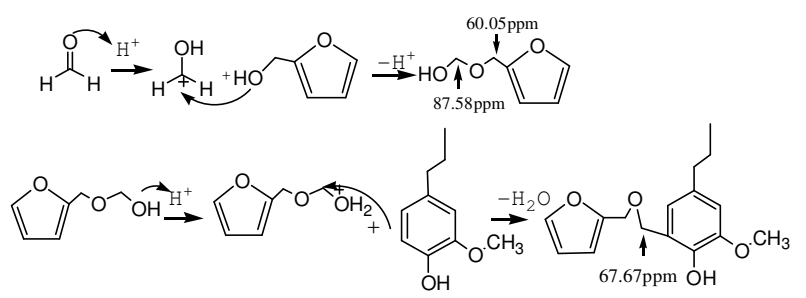<smiles>CCCCCCCc1cc(CCC)cc(OC)c1O</smiles>

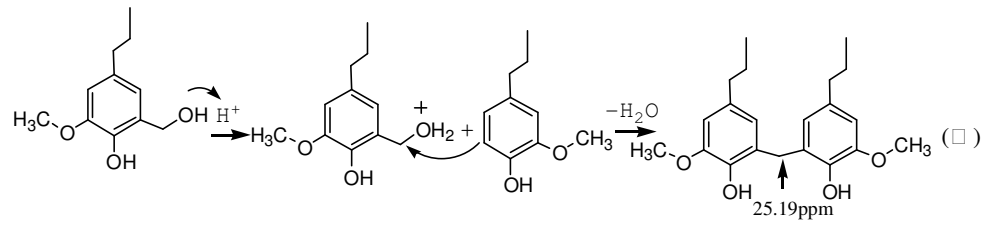

Scheme 1: Reaction of formaldehyde, furfuryl alcohol and lignin

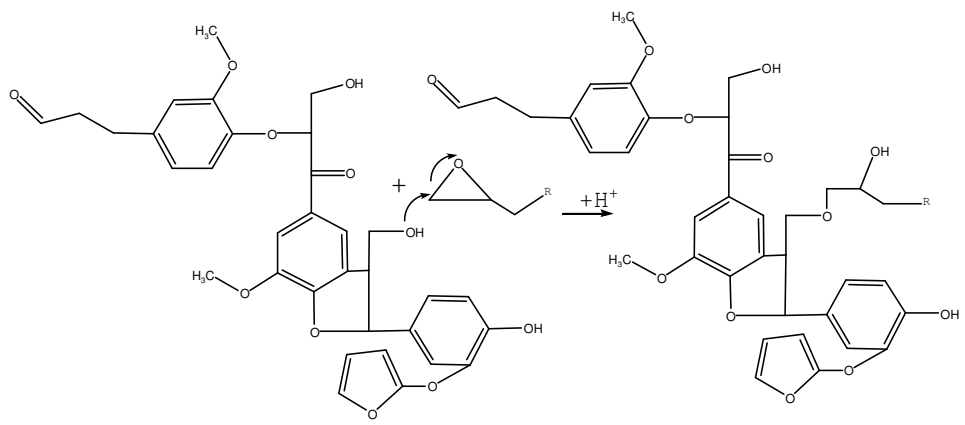

Scheme 2: Reaction of LFF oligomer and EPR 
MALDI-TOF-MS spectrometry

The results of MALDI-TOF analysis of the different oligomers formed during the preparation of the FF resin and LFF adhesives generated by the co-polymerization reaction of furfuryl alcohol, formaldehyde, lignin and EPR are shown in Figures 3, 4 and 5. The main chemical oligomer structures of the resins are shown in Table 3. All the peak values are based on the molecular weight (MW) of the species + $23 \mathrm{Da}$ due to the $\mathrm{Na}+$ ion of the $\mathrm{NaCl}$ matrix enhancer used, or $+1 \mathrm{Da}$ due to $\mathrm{H}+$ protonation. Figure 3 shows that the series of oligomers at 303.5, 325.5, 352.5, 374.3, and $380.4 \mathrm{Da}$ indicate that the co-reaction between furfuryl alcohol and formaldehyde has indeed been established. These varieties of oligomers were formed with linear oligomers linked by either methylene ether bridges, or by methylene bridges. ${ }^{17}$ The peaks at $380.4,303.5$, and $440-441$ $\mathrm{Da}$ belong to the dimers, tripolymers, and pentamers formed by the bridge-bonding of furfuryl alcohol monomers, but the hexamers and heptamers of furfuryl alcohol at 499 or $521 \mathrm{Da}$ and 579 or $601 \mathrm{Da}$ are not seen in Figure 3, indicating that the cross-linking between formaldehyde and furfuryl alcohol under acidic conditions decreased the self-condensation of furfuryl alcohol for further polymerization.

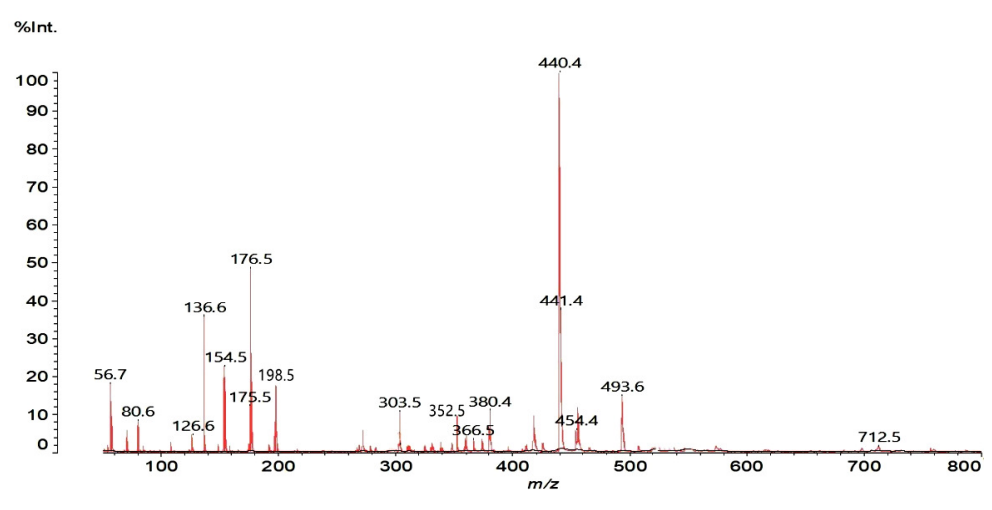

Figure 3: MALDI-TOF peaks of FF resin

Figure 4a shows a peak at $292.5 \mathrm{Da}$, indicating that the crosslinking between the guaiacyl monomer of lignin and furfuryl alcohol has been proven. The 601.3, 654.5, 726.1 and 756.1 Da peaks (Fig. 4b) belong to an oligomer formed by the reaction of furfuryl alcohol with guaiacyl tripolymer of lignin and formaldehyde. In addition, the two oligomers at 854.8 and 888.8 $\mathrm{Da}$ peaks appear to form with lignin, formaldehyde and furfuryl alcohol by methylene bridges or either methylene ether bridges. Moreover, from Figure 5, we can see that the peak at 331.5 Da belongs to an oligomer formed by the reaction of EPR and two furfuryl alcohol monomers. Meanwhile, the oligomer at 536.2 Da peak was formed by the crosslinking of lignin, formaldehyde, furfuryl alcohol and EPR. In terms of particleboard performance, the dry IB strength LFF+9\%EPR adhesive was better than that of the $\mathrm{PF}$ adhesive, and the establishment of a cross-link between FF resin and lignin contributed to the formation of the oligomers. These oligomers could easily cross-link EPR under acidic conditions during the curing process (Scheme 2). Numerous tertiary carbon hydroxyethyls existed in the LFF+9\%EPR adhesive. The three-dimensional network structure of LFF+9\%EPR adhesive in the curing process was formed by the cross-linking of tertiary carbon hydroxyethyls. 

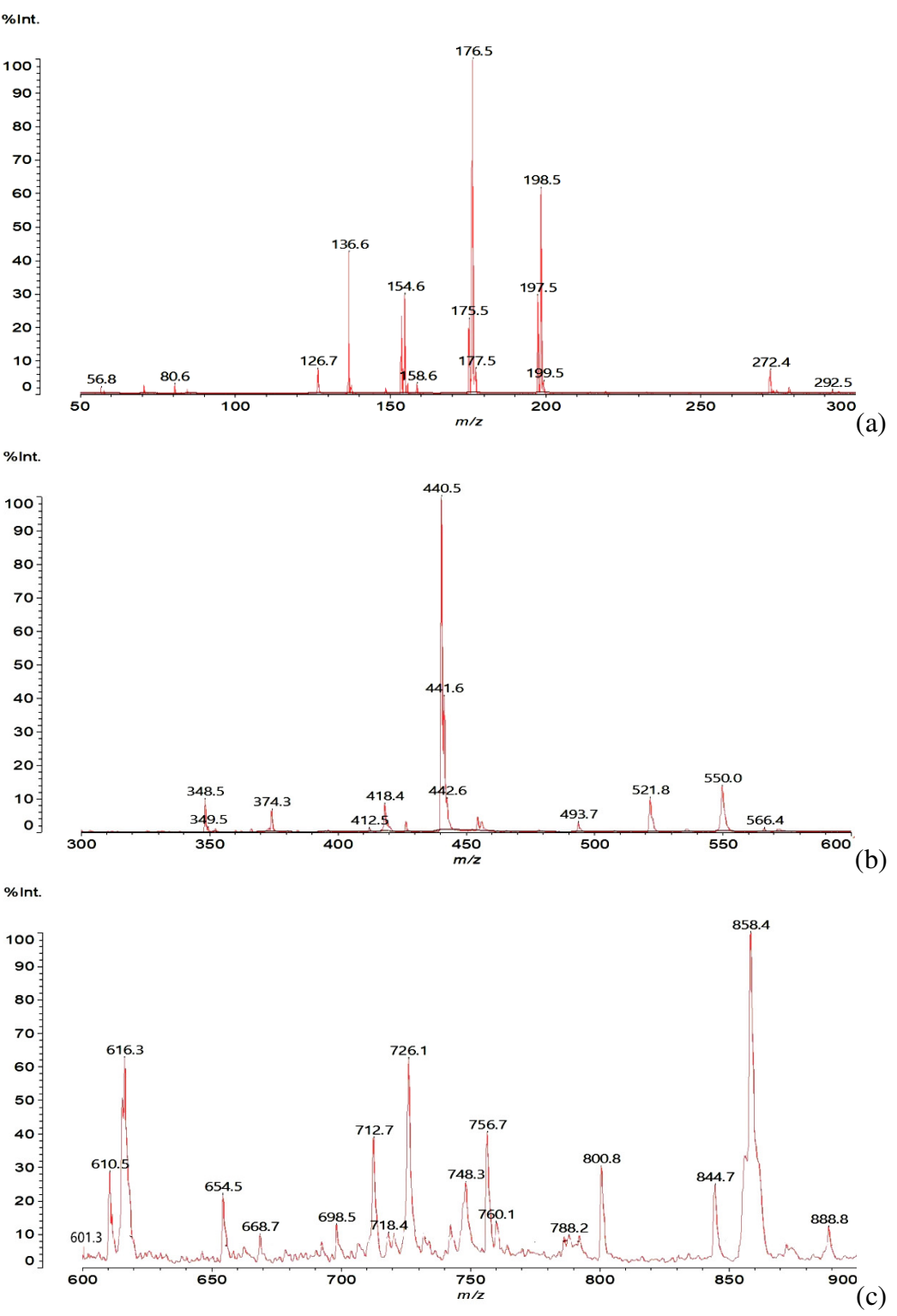

Figure 4: MALDI-TOF peaks of LFF adhesive: a) 50-300, b) 300-600, c) 600-800

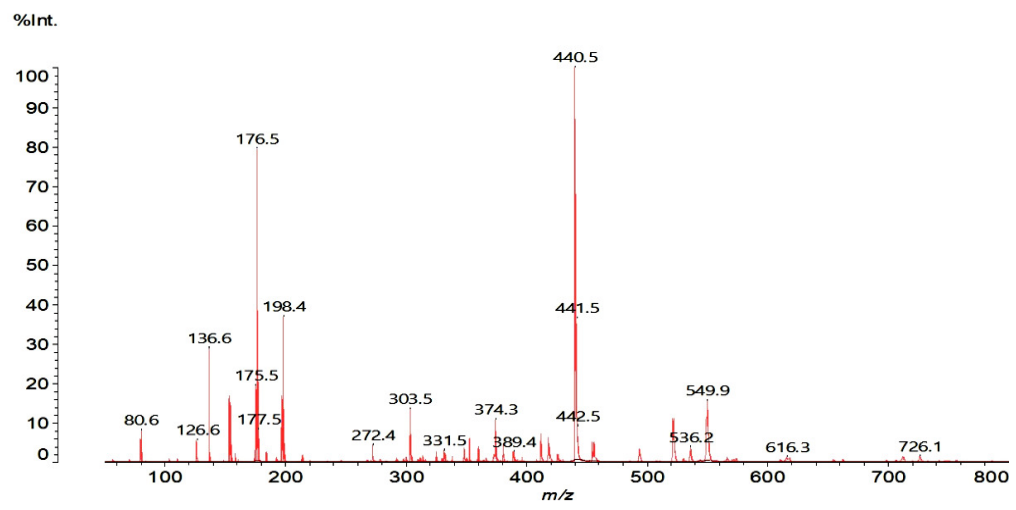

Figure 5: MALDI-TOF peaks of LFF+9\%EPR adhesive 


\section{JUN ZHANG et al.}

Table 3

Oligomers identified through MALDI-TOF mass spectrometry during the reaction among furfuryl alcohol + formaldehyde + lignin

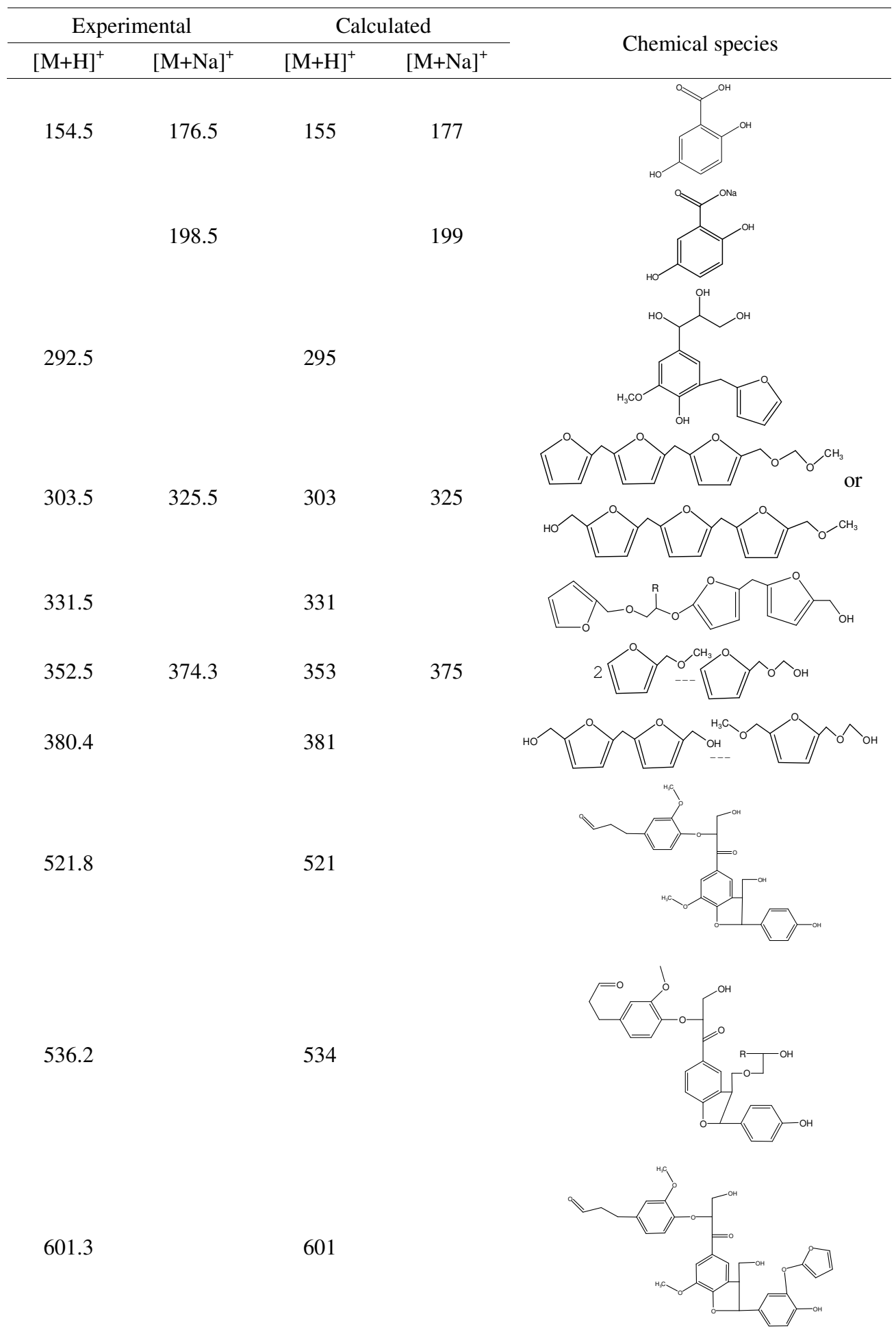


654.5

726.1

748.3

756.7

858.4
653

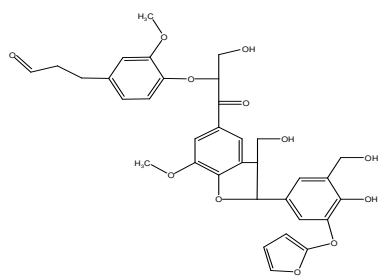

726

748

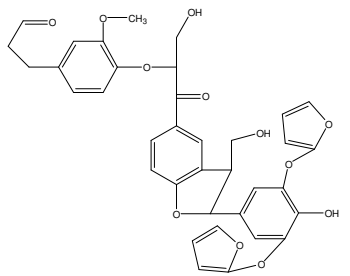

756
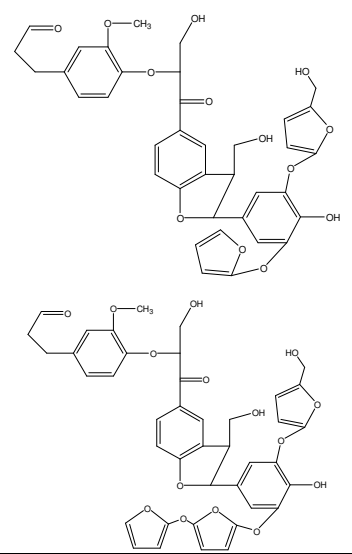

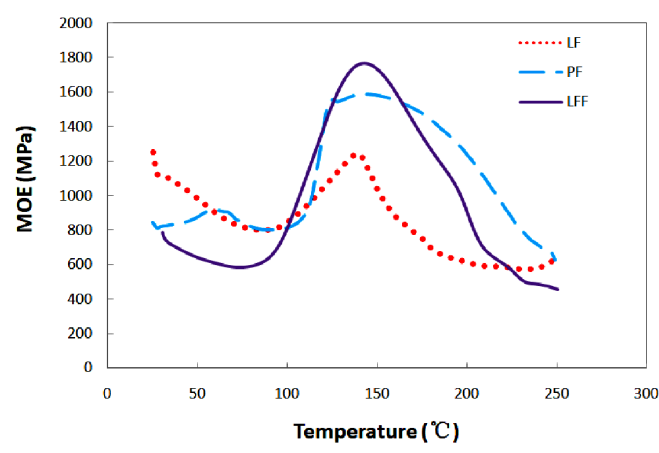

Figure 6: Thermomechanical analysis (TMA) of PF, LF and LFF adhesives

\section{TMA analysis}

Figure 6 shows the results of Modulus of Elasticity (MOE), hence of the maximum strength, obtained by the thermomechanical analysis (TMA) of joints bonded with PF- and lignin-based adhesives. The result indicates that the maximum MOE value of the panel bonded with LFF adhesive (1716 MPa) is higher than those of the panels bonded with PF (1589 MPa)

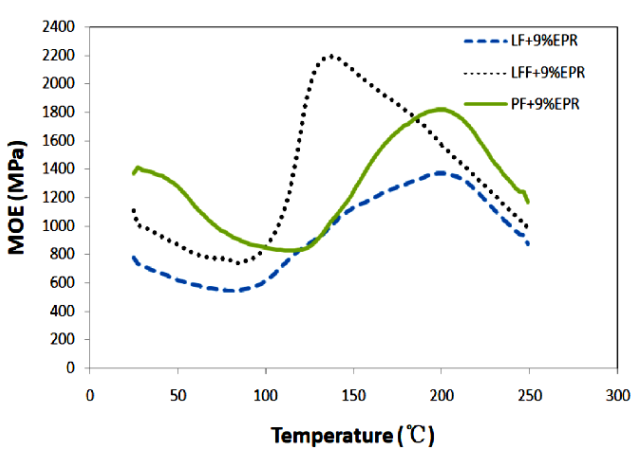

Figure 7: Thermomechanical analysis (TMA) of $\mathrm{PF}+9 \% \mathrm{EPR}, \mathrm{LF}+9 \% \mathrm{EPR}$ and $\mathrm{LFF}+9 \% \mathrm{EPR}$ adhesives

and LF adhesives (1244 MPa) and achieved the maximum strength of the joints bonded with the cross-linked LFF adhesive. Formaldehyde added to a LF resin system yields a higher MOE value than that of the LF adhesive. Meanwhile, the MOE results of $\mathrm{PF}+9 \%$ EPR and lignin-based $+9 \%$ EPR adhesives are displaced in Figure 7, indicating that the cross-linking between the lignin-based adhesives or PF adhesive and 
EPR has been proven to improve their MOE value, compared with the MOE values of the PF, LF and LFF adhesives. The MOE value of the panel prepared with LFF+9\% adhesive (2191 $\mathrm{MPa}$ ) presents an excellent strength of the joints.

\section{CONCLUSION}

In this paper, a new lignin-based wood adhesive is presented. Definite proportions of furfuryl alcohol and formaldehyde in water were pre-condensed for $30 \mathrm{~min}$ at $60{ }^{\circ} \mathrm{C}$ under acid conditions. This pre-polymer was then mixed with lignin at $\mathrm{pH} 5,60{ }^{\circ} \mathrm{C}$ for $30 \mathrm{~min}$. The ${ }^{13} \mathrm{C}$ NMR and MALDI-TOF results showed that a reaction between furfuryl alcohol and formaldehyde was present. The hydroxymethyl groups generated by this reaction appeared to be the reactive groups mediating the cross-linking of the LFF resin. To prepare a lignin-based adhesive with good water resistance, 9\% EPR was mixed with LFF resin during the curing process, which yielded a particleboard with good water resistance. The 2-h thickness swelling value of the particleboard bonded with LFF+9\%EPR adhesive was lower than that of the particleboard bonded with LF adhesive. The IB strength of particleboard bonded with LFF+9\%EPR adhesive was close to that of the particleboard bonded with PF adhesive. The MOE value of LFF+9\%EPR adhesive was higher than that of the PF adhesive. Thus, it can be concluded that it is a highly promising prospective industrial wood adhesive.

ACKNOWLEDGEMENTS: This work was financially supported by the Natural Science Foundation of China-Youth Fund (No. 31800482), the Yunnan Province Natural Science Foundation (No. 2017FB060) and the Science Foundation of Southwest Forestry University (No. 000033).

\section{REFERENCES}

1 Z. Wu, H. Lei, M. Cao, X. Xi, J. Liang et al., J. Adhes. Sci. Technol., 19, 1 (2016), https://doi.org/10.1080/01694243.2016.1175247

2 P. Dongre, M. Driscoll, T. Amidon and B. Bujanovic, Energies, 8, $7897 \quad$ (2015), https://doi.org/10.3390/en8087897

3 U. H. Abdullah and A. Pizzi, Eur. J. Wood Prod., 71 , 131 (2013), https://doi.org/10.1007/s00107-012-0629-4 4 J. Zhang, J. Liang, G. Du, X. Zhou, H. Wang et al., BioResources, 12, $6082 \quad$ (2017), https://doi.org/10.15376/biores.12.3.6082-6093
5 W. Yang, M. Rallini, M. Natali, J. Kenny, P. Ma et al., Mater. Design, 161, 55 (2019), https://doi.org/10.1016/j.matdes.2018.11.032

6 T. G. Rials and W. G. Glasser, Holzforschung, 40, 353 (1986), https://doi.org/10.1515/hfsg

7 Y. Nonaka, B. Tomita and Y. Hatano, Holzforschung, $\quad 51, \quad 183 \quad$ (1997), https://doi.org/10.1515/hfsg

8 E. A. Borges da Silva, M. Zabkova, J. D. Araujo, C A. Cateto, M. R. Barreiro et al., Chem. Eng. Res. Des., 87, 1276

(2009),

https://doi.org/10.1016/j.cherd.2009.05.008

9 J. H. Lora and W. G. Glasser, J. Polym. Environ., 10, 39

(2002), https://doi.org/10.1023/A:1021070006895

10 H.-L. Li, D. She, P. Peng, Q. Xu, J.-K. Liu et al., Cellulose Chem. Technol., 51, 433 (2017), http://www.cellulosechemtechnol.ro/pdf/CCT5-6(2017 )/p.433-445.pdf

11 F. G. Calco-Flores and J. A. Dobado, ChemSusChem, 3, $1227 \quad$ (2010), https://doi.org/10.1002/cssc.201000157

12 X. J. Li, A. Nicollin, A. Pizzi, X. J. Zhou, A. Sauget et al., RSC Adv., 3, 17732 (2013), https://doi.org/10.1039/C3RA43095B

13 C. Lacoste, M. C. Basso, A. Pizzi, M. P. Laborie, D. Garcia et al., Ind. Crop. Prod., 45, 401 (2013), https://doi.org/10.1016/j.indcrop.2012.12.032

14 G. Tondi, A. Pizzi, H. Pasch and A. Celzard, Polym. Degrad. Stabil., 93, 968 (2008), https://doi.org/10.1016/j.eurpolymj.2008.06.029

15 H. Pasch, A. Pizzi and K. Rode, Polymer, 42, 7531 (2001), https://doi.org/10.1016/S0032-3861(01)00216-6 16 N. Guigo, A. Mija, L. Vincent and N. Sbirrazzuoli, Phys. Chem. Chem. Phys., 9, 5359 (2007), https://doi.org/10.1039/b707950h

17 X. D. Xi, A. Pizzi, C. Gerardin, H. Lei and G. B. Du, J. Adhes., Online 1/10/2018 (2018), https://doi.org/10.1080/00218464.2018.1519435

18 D. H. Retief, C. J. Dreyer and G. Gavron, Am. J. Orthod., $\quad \mathbf{5 8 ,} \quad 21 \quad$ (1970). https://doi.org/10.1016/0002-9416(70)90126-0

19 F. Lapique and K. Redford, Int. J. Adhes. Adhes., 22, $337 \quad$ (2002), https://doi.org/10.1016/S0143-7496(02)00013-1

20 F. Ferdosian, Y. Zhang, Z. Yuan, M. Anderson and C. Xu, Eur. Polym. J., 82, 153 (2016), https://doi.org/10.1016/j.eurpolymj.2016.07.014

21 M. Elbadawi, Z. Osman, T. Paridah, T. Nasroun and W. Kantiner, Cellulose Chem. Technol, 49, $369 \quad$ (2015), http://www.cellulosechemtechnol.ro/pdf/CCT3-4(2015 )/p.369-374.pdf 